\title{
CONTAGION ACROSS REAL ESTATE AND EQUITY MARKETS DURING EUROPEAN SOVEREIGN DEBT CRISIS
}

\author{
Eddie C. M. HUI $1 \bowtie$ and Ka Kwan Kevin CHAN ${ }^{2}$ \\ ${ }^{1}$ Department of Building and Real Estate, The Hong Kong Polytechnic University, Hong Kong, \\ China \\ E-mail: bscmhui@polyu.edu.hk \\ ${ }^{2}$ Department of Building and Real Estate, The Hong Kong Polytechnic University, Hong Kong, \\ China \\ E-mail:ckkwyc@yahoo.com.hk
}

Received 16 April 2012; accepted 6 June 2012

\begin{abstract}
Standard methods of testing contagion may not work well if the data set is not normally distributed. To cope with this problem, Hatemi-J and Hacker (2005) proposed a new case-resampling bootstrap method to test contagion. In this paper, we extend this method to test the parameters in the Forbes-Rigobon multivariate (FRM) test. The new method has the advantage that the bivariate model is extended to a multivariate framework which jointly models and tests all combinations of contagious linkages. We apply our method to investigate contagion across equity and real estate markets of four countries: Greece, U.K., U.S. and Hong Kong, during the European sovereign debt crisis, and compare the result with that by performing the FRM test directly. Two important results are found. Firstly, both tests we use give similar p-values of the coefficients which indicate the significance of contagion. Secondly, for both tests, the contagion pattern in the equity and real estate markets are different. Our study has an implication to investors that they should regularly review their portfolio and be aware of contagion triggered by a crisis. This would help them reduce their loss and is useful in strategic property management.
\end{abstract}

KEYWORDS: Contagion; European sovereign debt crisis; Normality; Linear regression; Caseresampling bootstrap method

REFERENCE to this paper should be made as follows: Hui, E. C. M. and Chan, K. K. K. (2013) Contagion across real estate and equity markets during European sovereign debt crisis, International Journal of Strategic Property Management, 17(3), pp. 305-316.

\section{INTRODUCTION}

Most investors are risk-averse, i.e. they seek for opportunities to reduce the risk of their investment. A well-known method of reducing risk is diversification. Therefore, investors are always advised to invest in different types of asset in different countries in order to diversify their risk. However, during a financial crisis, correlation of a type of asset market between two countries usually increases. They often move down together due to a worsening environment. Even correlation between different types of asset markets may increase, too. As a result, the opportunity of diversification is reduced. This phenomenon is called contagion. The World Bank Group (2011) gives three definitions of contagion:

Broad definition: contagion is the crosscountry transmission of shocks or the general cross-country spillover effects. 
Restrictive definition: contagion is the transmission of shocks to other countries or the cross-country correlation, beyond any fundamental link among the countries and beyond common shocks.

Very restrictive definition: contagion occurs when cross-country correlations increase during "crisis times" relative to correlations during "tranquil times".

Most of the literatures adopted the very restrictive definition of contagion given by the World Bank. Our paper also adopts the World Bank's very restrictive definition of contagion. There are also other definitions of contagion. For example, Pericoli and Sbracia (2003) stated five definitions of contagion which are adopted in some literatures.

As mentioned, contagion usually occurs during "crisis times", when shocks transmit from a country to others, causing co-movements (usually downward) of asset prices. There are a number of crises triggering shocks around the world. The most typical one is the Great Depression in the 30's, causing the deepest global recession ever. Other crises include the oil crisis in the 70's, the 1987 U.S. stock market crash, the 1994 Mexico Peso crisis, the 1997-1998 East Asian crisis, the 2008 global financial tsunami and the current European sovereign debt crisis. In particular, the financial tsunami in 2008, when nearly all risky assets fell together at the same time, was the worst global financial crisis since the Great Depression. Many investors lost a lot on their investment. If they knew that there was a sign of contagion (e.g. when the correlation between two assets suddenly increases sharply, which is the simplest indication of contagion), they might be able to reallocate their investment to minimize their loss. Furthermore, the contagion patterns in the past crises can act as reference for examining contagion patterns in future crises. Therefore, it is important to study contagion. Due to this importance, the topic of contagion has attracted a number of people to study on in the past.

Our work adds value on existing literature on three ways. Firstly, previous literature on contagion mostly studied equity markets (e.g. Forbes and Rigobon, 2002). However, there was an increasing concern on contagion across real estate markets in recent years. According to Hudson-Wilson et al. (2003), real estate can reduce overall portfolio risk, achieve high absolute returns and hedge unexpected inflation or deflation. Hence there are additional motivations for investors to include real estate in their portfolio. Therefore, it is increasingly important to study contagion across real estate markets. Moreover, as mentioned by Hatemi-J and Roca (2010), the recent globalization and internationalization of real estate markets lead to increasing integration, which is expected to cause more co-movements of prices among global real estate markets. However, according to Hui and Zheng (2012b), real estate is a special commodity which can act not only as consumption goods, but also as in investment tool. Due to this special feature of real estate, the contagion pattern of real estate markets may not be the same as those of other asset markets, so it is worth studying the contagion among global real estate markets. Furthermore, the limited number of previous works on this topic has led to mixed results (see Section 2). This paper contributes to the limited research on whether there is contagion between real estate markets.

Secondly, most of the previous work studied the Asian financial crisis in 1997 (e.g. Bond et al., 2006; Wilson and Zurbruegg, 2004). There are also a few articles about contagion across asset markets during the global financial tsunami in 2008, like Fry et al. (2010) and Dungey (2009). However, the European sovereign debt crisis happened just recently, so there are still no publications on contagion across asset markets during the crisis. This crisis involves emerging markets in Europe which previous studies seldom worked on, so we do not know much about the contagion patterns among these countries. This is the main motivation of our research. This paper fills in the missing gap that contagion in real estate markets during European sovereign debt crisis was insufficiently addressed in previous works. 
Furthermore, the majority of methodologies used in previous literature are based on correlation. For example, Forbes and Rigobon (2002) used the ordinary correlation coefficient to derive the adjusted correlation coefficient, and hence constructed the Forbes-Rigobon test for contagion. Many other tests, such as the Chow test (Dungey, 2005a), the coskewness test (Fry et al., 2010) and the cokurtosis test (Hui and Chan, 2012), are extensions of the Forbes-Rigobon test. However, as Hatemi-J and Roca (2010) pointed out, the above standard methods may not work well on data which do not satisfy the conditions of normality and constant variance. To cope with this problem, Hatemi-J and Hacker (2005) proposed a caseresampling bootstrap method to test contagion, and applied this method to test for contagion from Thai to Indonesian equity markets during the Asian financial crisis. Their approach is applied by Hatemi-J and Roca (2010) to test contagion across real estate markets of different countries during the U.S. subprime crisis. As previous studies applied this method on a bivariate model only, we extend their bivariate approach to a multivariate framework. This multivariate framework jointly models and tests all combinations of contagious linkages. Thus it has an advantage that all directions of contagion can be tested, so we get a more complete picture of the contagion pattern.

In this paper, we investigate contagion across equity and real estate markets of four countries: Greece, U.S., U.K., and Hong Kong, during the European sovereign debt crisis. We use the FRM test and the case-resampling bootstrap method, and compare the results of the two different tests. We extend the caseresampling bootstrap method to our multivariate framework so that all contagious linkages can be tested. We highlight the importance of the case-resampling bootstrap method that it performs well under non-normality and heteroscedasticity, which standard methods do not work well in these cases.

The paper proceeds as follows. Section 2 reviews previous works on contagion across real estate markets. In Section 3, we describe the tests of contagion we use. In Section 4, we explained how the crisis period and the indices are selected. Section 5 gives the results of the tests and an analysis of the results. We draw up conclusion and provide a further discussion of the topic in Section 6.

\section{LITERATURE REVIEW}

This section gives a review of previous studies on contagion across real estate markets (or contagion between real estate and equity markets). The following is a list of part of such studies. Bond et al. (2006) investigated the contagion across real estate markets during the 1997-98 East Asian crisis using the latent factor model, and found that contagion among the markets existed. On the contrary, Fry et al. (2010), who tested the existence of contagion across global real estate markets during the East Asian crisis and the U.S. subprime crisis using higher order moments, found no significant evidence of contagion. Using the Forbes-Rigobon test, Wilson and Zurbruegg (2004) examined contagion from the Thai real estate market to other East Asian real estate markets during the 1997 Asian crisis. They found only little evidence of contagion. Wilson et al. (2007) applied the method of structural time series to measure spillover effects across Asian property markets during the Asian financial crisis in 1997. They found a broad level of interdependence that transcended the Asian financial crisis. Yunus and Swanson (2007) applied a number of tests to examine long-run relationships and short-run causal linkages among the public property markets of the Asia-Pacific region and the U.S. over from January 2000 to March 2006. In the short run, there were no significant lead-lag relationships between the property markets of the U.S. and the Asia-Pacific region. While in the long run, from the perspective of U.S. investors, Hong Kong and Japan's markets provided greater diversification benefits. Hence U.S. real estate investors could benefit from diversification both in the short and long run. Liow (2008) investigated the changes in long-run 
relationship and short-term linkage among the US, UK and eight Asian securitized real estate markets before, during, and after the 1997-1998 Asian financial crisis as well as in the most recent period. He found a stronger interdependence in Asian securitized real estate markets since the Asian financial crisis, both in the long run and in the short run. Furthermore, this interdependence seemed to be on a rising trend recently. Yunus (2009) examined the degree of interdependence among the securitized property markets of six major countries and the U.S. He found that over a period from January 1990 to August 2007, the property markets of Australia, Hong Kong, Japan, the United Kingdom and the U.S. were tied together. Ryan (2011) implemented a specific class of Vector Autoregression (VAR) models to examine the level of integration between international listed property markets during the Asian financial crisis and the current global credit crisis. The result showed that diversification benefits evaporated during the crisis in both hedged and un-hedged cases as a result of cointegration between the markets. Hui and Chan (2012), who used the coskewness and cokurtosis tests to examine contagion between U.S., U.K., China and Hong Kong during the financial tsunami in 2008, found significance evidence between those countries. In particular, the greatest significance of contagion was found between China and Hong Kong, and between U.S. and U.K. Hui and Zheng (2012a) investigated the dynamic conditional correlations (DCCs) between housing returns and retail property returns, and the existence of volatility spillover between the two property markets of Hong Kong. From the findings, they suggested that Hong Kong's retail property market was generally more volatile than the residential market. They also found a unilateral volatility spillover from residential property to retail property in the Hong Kong market. Serrano and Hoesli (2012) used fractional cointegration analysis to examine the existence of long-run relations between securitized real estate returns and three sets of variables frequently used in the literature as the factors driving securitized real estate returns. They found strong evidence of fractional cointegration between securitized real estate and the three sets of variables.

Some people did research on integration/interdependence between real estate and equity markets. For example, Okunev and Wilson (1997) tested whether or not there existed a relationship of co-integration between the REIT and the S\&P 500 indices. The results indicated that the real estate and stock markets were fractionally intergrated. Okunev et al. (2000) conducted both linear and nonlinear causality tests on the US real estate and the S\&P 500 Index and concluded that there exists unidirectional relationship from real estate to stock market when using the linear test, but there is a strong unidirectional relationship from the stock market to the real estate market when using the nonlinear test. Knight et al. (2005) constructed models of asymmetric dependence using the copula function to examine the relationship between securitized real estate and equity markets. They found that for both U.K. and global markets, the securitized real estate and equity markets exhibited strong tail dependence - particularly in the negative tail, suggesting that real estate securities offer, at best, limited diversification protection when other asset markets were falling. Zhou (2010) applied the wavelet analysis to examine the comovement among international securitized real estate markets and the cross-market comovement between the stock and securitized real estate markets. Using data from 17 different countries over 14 years, Quan and Titman (1999) found a significant positive relation between stock returns and changes in commercial real estate values. Some studies found a long-term positive correlation between real estate and stock prices. Tse (2001) studied the impact of property prices on stock prices in Hong Kong from 1974 to 1998, and found that the property and stock prices are cointegrated. Liow (2006) also found long-term positive correlations between real estate and stock prices in general. Similar results were found by Hui et al. (2011), who examined the relationship 
between real estate and stock markets in U.K. and Hong Kong by the method of data mining. They found not only a positive correlation, but also a co-movement, between the two markets. Case et al. (2012) used the Dynamic Conditional Correlation model with Generalized Autoregressive Conditional Heteroskedasticity (DCC-GARCH) to examine dynamics in the correlation of returns between publicly traded REITs and non-REIT stocks. They found that REIT-stock correlations formed three distinct periods. Liow (2012) investigated comovements and correlations across eight Asian securitized real estate markets over 1995-2009, and found that real estate-global stock correlations co-moved significantly and positively with real estate-regional stock correlations and real estate-local stock correlations. The above research studies are evidences that the cointegration between equity and real estate markets is stronger than before.

The above summarizes previous literatures on contagion across real estate markets. In the next section, we describe two of the contagion tests: the Forbes-Rigobon multivariate (FRM) test (also called the multivariate version of Chow test) and the case-resampling bootstrap method.

\section{TESTS OF CONTAGION}

\subsection{The Chow test and its multivariate version}

Dungey et al. (2005a) proposed the Chow test of contagion. One of its advantages is that it provides a natural extension of the bivariate approach to a multivariate framework that jointly models and tests all combinations of contagious linkages. The main idea is to use linear regression. For example, to test contagion from country $i$ to country $j$, the equation of regression is

$$
\frac{z_{j, t}}{\sigma_{x, j}}=\gamma_{0}+\gamma_{1} d_{t}+\gamma_{2}\left(\frac{z_{i, t}}{\sigma_{x, i}}\right)+\gamma_{3}\left(\frac{z_{i, t}}{\sigma_{x, i}}\right) d_{t}+\varepsilon_{t},(1)
$$

where:

$$
z_{i}=\left(x_{i, 1}, \ldots, x_{i, T_{x}}, y_{i, 1}, \ldots, y_{i, T_{y}}\right)^{\prime}
$$

represents the $\left(T_{x}+T_{y}\right) \times 1$ scaled pooled data set by stacking the pre-crisis and crisis scaled data; $\sigma_{x, i}$ denotes the standard deviation of the asset price of country $i$ in the pre-crisis period; $T_{x}$ and $T_{y}$ denote the sample sizes of the pre-crisis and crisis periods respectively; and $d_{t}$ is a dummy variable defined by:

$$
d_{t}=\left\{\begin{array}{c}
1, t>T_{x} \\
0, \text { otherwise }
\end{array}\right.
$$

and $\varepsilon_{t}$ is an error term.

The null hypothesis is

$$
H_{0}: \gamma_{3}=0
$$

against the alternative hypothesis of

$$
H_{1}: \gamma_{3}>0
$$

Hence, to test the null hypothesis of no contagion, we can perform a one-sided t-test to $\frac{\hat{\gamma}_{3}}{\hat{\sigma}_{3}}$, where $\hat{\gamma}_{3}$ is the ordinary least square (OLS) estimator of $\gamma_{3}$, and $\hat{\sigma}_{3}$ is the standard error of $\hat{\gamma}_{3}$.

To study contagion, usually three or more countries are involved. For the sake of convenience, there is a multivariate version of the Chow test, which is also called the ForbesRigobon multivariate (FRM) test. For example, for three countries, the set of equations is (Dungey et al., 2005b):

$$
\begin{aligned}
& \frac{z_{1, t}}{\sigma_{x, 1}}=\alpha_{1,0}+\alpha_{1, d} d_{t}+\alpha_{1,2}\left(\frac{z_{2, t}}{\sigma_{x, 2}}\right)+\alpha_{1,3}\left(\frac{z_{3, t}}{\sigma_{x, 3}}\right)+ \\
& \gamma_{1,2}\left(\frac{z_{2, t}}{\sigma_{x, 2}}\right) d_{t}+\gamma_{1,3}\left(\frac{z_{3, t}}{\sigma_{x, 3}}\right) d_{t}+\varepsilon_{1, t}, \\
& \frac{z_{2, t}}{\sigma_{x, 2}}=\alpha_{2,0}+\alpha_{2, d} d_{t}+\alpha_{2,1}\left(\frac{z_{1, t}}{\sigma_{x, 1}}\right)+\alpha_{2,3}\left(\frac{z_{3, t}}{\sigma_{x, 3}}\right)+ \\
& \gamma_{2,1}\left(\frac{z_{1, t}}{\sigma_{x, 1}}\right) d_{t}+\gamma_{2,3}\left(\frac{z_{3, t}}{\sigma_{x, 3}}\right) d_{t}+\varepsilon_{2, t}, \\
& \frac{z_{3, t}}{\sigma_{x, 3}}=\alpha_{3,0}+\alpha_{3, d} d_{t}+\alpha_{3,1}\left(\frac{z_{1, t}}{\sigma_{x, 1}}\right)+\alpha_{3,2}\left(\frac{z_{2, t}}{\sigma_{x, 2}}\right)+ \\
& \gamma_{3,1}\left(\frac{z_{1, t}}{\sigma_{x, 1}}\right) d_{t}+\gamma_{3,2}\left(\frac{z_{2, t}}{\sigma_{x, 2}}\right) d_{t}+\varepsilon_{3, t},
\end{aligned}
$$


where: $z_{i}$ are defined by (2); $d_{t}$ is defined by (3); and $\varepsilon_{i, t}$ are error terms. To test contagion from country $i$ to country $j$, the null hypothesis is $\gamma_{j, i}=0$, and we can apply a one-sided t-test to $\frac{\hat{\gamma}_{j, i}}{\hat{\sigma}_{j, i}}$, where $\hat{\gamma}_{j, i}$ is the OLS estimator of $\gamma_{j, i}$, and $\hat{\sigma}_{j, i}$ is the standard error of $\hat{\gamma}_{j, i}$.

Remark:

1. In equation (6), it is not strictly necessary to standardize the data $z_{i, t}$.

2. We follow Forbes and Rigobon (2002)'s assumption of no endogeneity between markets.

\subsection{The case-resampling bootstrap method}

The Chow test described in the previous section has a disadvantage that if the data set is not normally distributed, or its variance is not constant, then the result may not be accurate. To cope with this problem, Hatemi-J and Hacker (2005) developed an alternative test of contagion using the case-resampling bootstrap method. One advantage of this method is that it performs accurately when the assumption of normality and constant variance is not fulfilled (Hatemi-J and Roca, 2010). Hatemi-J and Hacker (2005) also presented simulations on how well the case-resampling bootstrap method worked, and suggested that it worked better than the OLS method. Hatemi-J and Hacker (2005), Hatemi-J and Roca (2010) applied this method to estimate the coefficient $\gamma_{3}$ in the single equation (1) (their equation is different from ours that $z_{i, t}$ is not divided by $\sigma_{x, i}$ ) and use a two-sided test to test its significance. For details of proof of this method, please refer to Hatemi-J and Hacker (2005).
The case-resampling bootstrap method can be applied to estimate the coefficients in the set of equations (6) of the FRM model. In this paper, we extend Hatemi-J and Hacker (2005)'s approach to a multivariate framework that jointly models and tests all combinations of contagious linkages. We use a one-sided test to test the significance of contagion. For each of the equations in (6), we undergo the following procedure (the steps are similar to those of Hatemi-J and Roca (2010), but we apply them to our multivariate model):

1. For $T=T_{x}+T_{y}$ given observations, select $T$ of them randomly with replacement.

2. For these $T$ randomly selected observations, compute the OLS estimator of the coefficients $\gamma_{j, i}$.

3. Repeat steps 1 and $2 N$ times so that for each coefficient $\gamma_{j, i}$, we obtain $N$ estimations $\hat{\gamma}_{j, i}^{1}, \hat{\gamma}_{j, i}^{2}, \ldots, \hat{\gamma}_{j, i}^{N}$.

4. The boostrap estimation $\hat{\gamma}_{j, i}^{*}$ of the coefficient $\gamma_{j, i}$ is given by the median of all $N$ estimations $\hat{\gamma}_{j, i}^{1}, \hat{\gamma}_{j, i}^{2}, \ldots, \hat{\gamma}_{j, i}^{N}$, while its $\mathrm{p}$-value is equal to (number of $\hat{\gamma}_{j, i}^{k}<0$ ) $/ N$. Note that we include only those $\hat{\gamma}_{j, i}^{k}$ which are negative in the numerator since we are conducting a one-sided test. In this paper, we set $N=500$.

\section{DATA SOURCE}

In the previous section, we described two tests of contagion: the Chow test and the case-resampling bootstrap method. We apply these two tests to test contagion across equity and real estate markets of four countries: Greece, U.K., U.S. and Hong Kong, during the European

Table 1. The equity and real estate indices chosen

\begin{tabular}{lll}
\hline & Equity index & Real estate index \\
\hline Greece & Athex Composite Index & Greece-DS Real Estate \\
U.K. & FTSE 100 Index & UK-DS Real Estate \\
U.S. & Dow Jones U.S. Total Stock Market Index & US-DS Real Estate \\
Hong Kong & Hang Seng Index & Hong Kong-DS Real Estate \\
\hline
\end{tabular}


Table 2. The descriptive statistics

\begin{tabular}{|c|c|c|c|c|c|c|c|c|c|}
\hline & & \multicolumn{4}{|l|}{ Equity } & \multicolumn{4}{|c|}{ Real estate } \\
\hline & & Greece & UK & US & HK & Greece & UK & US & HK \\
\hline \multirow{2}{*}{$\begin{array}{l}\text { Whole } \\
\text { period }\end{array}$} & Mean & -0.00166 & 0.00056 & 0.00050 & 0.00035 & -0.00134 & 0.00051 & 0.00133 & -0.00019 \\
\hline & $\mathrm{SD}$ & 0.02254 & 0.01130 & 0.01197 & 0.01411 & 0.02021 & 0.01658 & 0.02062 & 0.01624 \\
\hline \multirow{2}{*}{$\begin{array}{l}\text { Pre-crisis } \\
\text { period }\end{array}$} & Mean & -0.00038 & 0.00154 & 0.00137 & 0.00079 & -0.00048 & 0.00149 & 0.00225 & 0.00045 \\
\hline & SD & 0.02009 & 0.00993 & 0.01013 & 0.01446 & 0.01816 & 0.01597 & 0.01928 & 0.01649 \\
\hline \multirow{2}{*}{$\begin{array}{l}\text { Crisis } \\
\text { period }\end{array}$} & Mean & -0.00585 & -0.00265 & -0.00234 & -0.00111 & -0.00417 & -0.00270 & -0.00168 & -0.00227 \\
\hline & SD & 0.02878 & 0.01448 & 0.01633 & 0.01279 & 0.02559 & 0.01808 & 0.02427 & 0.01521 \\
\hline
\end{tabular}

sovereign debt crisis. We select these countries because Greece is the centre of shock of the European sovereign debt crisis, while U.K., U.S. and Hong Kong are the financial centres in Europe, North America and Asia respectively.

Before conducting the tests, we have to select the data for the tests first. We select the following equity and real estate indices for the four countries (see Table 1).

All indices are daily equity price indices obtained from Datastream. The equity indices are the major stock indices of each of the four countries which cover most of the largest listed companies of the countries. The real estate indices are, in fact, real estate stock indices (or securitized real estate indices) compiled by Datastream. The returns are computed as the difference of the natural logarithms of daily price indices.

The whole period of observation is set to be from July 1, 2009 to June 30, 2010, a total of 261 observations. We divide the whole timeline into pre-crisis and crisis periods as follows:

- Pre-crisis period: July 1, 2009 to April 6, 2010 (200 observations).

- Crisis period: April 7, 2010 to June 30, 2010 (61 observations).

We choose April 7 as the start of the crisis period as the indices began to fall more sharply than before since that day, indicating worsening of the crisis.

Now we can apply the two tests described in Section 3 to the data selected over the period of observation. The test results are shown in the next section.

\section{RESULTS OF THE TESTS}

\subsection{Preliminary statistics}

We obtain the daily equity and real indices of the four countries over the period of observation, and calculate the continuous compounded daily return of the indices. We first calculate the mean and standard deviation of the returns of the indices throughout the whole period, and in the two separate periods specified in Section 4, as shown in the Table 2.

From the Table 2, we can see that for both equity and real estate markets, the average returns of the indices of all four countries are lower in the crisis period than in the pre-crisis period. The standard deviations of the index returns of most countries increase, except for Hong Kong that both the equity and the real estate markets become slightly less volatile in the crisis period.

Next, we use the Anderson-Darling test to test for normality of the data. The result of the normality test is shown in the Table 3 .

From the Table 3, we can see that for both equity and real estate markets, the p-values of the normality test of most countries are very small (except for Hong Kong), showing that the null hypothesis of normality is strongly rejected. Hence the standard approaches to test for contagion, like the Chow test, may not work well in our case.

\subsection{Results of the contagion tests and analysis}

Here we apply the FRM test and the case-resampling bootstrap method to the data obtained. Tables 4, 5, 6 and 7 show the results of the tests. 
Table 3. The result of the normality test

\begin{tabular}{|c|c|c|c|c|c|c|c|c|}
\hline & \multicolumn{4}{|l|}{ Equity } & \multicolumn{4}{|c|}{ Real estate } \\
\hline & Greece & UK & US & HK & Greece & UK & US & HK \\
\hline P-value & 0.019 & $<0.005$ & $<0.005$ & 0.213 & $<0.005$ & $<0.005$ & 0.074 & 0.611 \\
\hline
\end{tabular}

Table 4. The result of the FRM test on the equity markets

\begin{tabular}{llllll}
\hline \multirow{2}{*}{$\hat{\gamma}_{j, i}$} & & Recipient & & \\
\cline { 3 - 5 } Source & Greece & Greece & UK & US & HK \\
& UK & -0.04885 & -0.08081 & 0.23951 & -0.18863 \\
& US & 0.26153 & -0.17320 & 0.17150 & 0.41034 \\
& HK & -0.02394 & 0.63730 & -0.62860 & -0.31076 \\
\hline P-value & & Recipient & & & \\
\cline { 3 - 6 } & Greece & UK & US & HK \\
\hline Source & Greece & & 0.803292 & 0.026831 & 0.928177 \\
& UK & 0.613171 & & 0.101442 & 0.004411 \\
& US & 0.027820 & 0.982145 & & 0.991597 \\
& HK & 0.549372 & 0.000000 & 0.999837 & \\
\hline
\end{tabular}

Table 5. The result of the FRM test on the real estate markets

\begin{tabular}{|c|c|c|c|c|c|}
\hline \multirow{2}{*}{$\hat{\gamma}_{j, i}$} & & \multicolumn{4}{|l|}{ Recipient } \\
\hline & & Greece & UK & US & HK \\
\hline \multirow[t]{4}{*}{ Source } & Greece & & 0.06688 & 0.06991 & -0.07445 \\
\hline & UK & 0.28727 & & 0.22932 & 0.26734 \\
\hline & US & 0.10132 & 0.01121 & & -0.15279 \\
\hline & HK & -0.04103 & 0.30192 & -0.20397 & \\
\hline \multirow[t]{2}{*}{$\mathrm{P}$-value } & & Recipient & & & \\
\hline & & Greece & UK & US & HK \\
\hline \multirow[t]{4}{*}{ Source } & Greece & & 0.268434 & 0.278361 & 0.737132 \\
\hline & UK & 0.055679 & & 0.061883 & 0.040804 \\
\hline & US & 0.255600 & 0.461521 & & 0.868494 \\
\hline & HK & 0.587404 & 0.018908 & 0.889575 & \\
\hline
\end{tabular}

From the tables, both the FRM test and the case-resampling bootstrap method show that the patterns of contagion in the equity and real estate markets are different. From Table 4, the FRM test shows that for the equity market, at 5\% significance level, there is significant evidence of contagion between Greece and U.S., and between U.K. and Hong Kong, in both directions. However, for the real estate market, at 5\% significance level, significant evidence of contagion is found only between
U.K. and Hong Kong, in both directions. All other contagious linkages are insignificant at $5 \%$ significance level, as seen from Table 5 . From Tables 6 and 7, we can find similar results shown by the case-resampling bootstrap method. The only difference is that the case resampling bootstrap method shows significance evidence of contagion in the real estate market from U.K. to Greece, but the FRM test shows that contagion in this direction is insignificant. 
Table 6. The result of the case-resampling bootstrap method on the equity markets

\begin{tabular}{|c|c|c|c|c|c|}
\hline \multirow{2}{*}{$\hat{\gamma}_{j, i}^{*}$} & & \multicolumn{4}{|l|}{ Recipient } \\
\hline & & Greece & UK & US & HK \\
\hline \multirow[t]{4}{*}{ Source } & Greece & & -0.06552 & 0.23969 & -0.18083 \\
\hline & UK & -0.04239 & & 0.18120 & 0.40409 \\
\hline & US & 0.26209 & -0.18082 & & -0.29404 \\
\hline & $\mathrm{HK}$ & -0.04660 & 0.62331 & -0.63245 & \\
\hline \multirow[t]{2}{*}{ P-value } & & Recipient & & & \\
\hline & & Greece & UK & US & HK \\
\hline \multirow[t]{4}{*}{ Source } & Greece & & 0.748 & 0.028 & 0.952 \\
\hline & UK & 0.608 & & 0.158 & 0.000 \\
\hline & US & 0.022 & 0.972 & & 0.992 \\
\hline & $\mathrm{HK}$ & 0.572 & 0.000 & 1.000 & \\
\hline
\end{tabular}

Table 7. The result of the case-resampling bootstrap method on the real estate markets

\begin{tabular}{llllll}
\hline \multirow{2}{*}{$\hat{\gamma}_{j, i}^{*}$} & & \multicolumn{2}{l}{ Recipient } & US & HK \\
\cline { 3 - 5 } Source & Greece & Greece & UK & 0.05276 & -0.08166 \\
& UK & 0.29991 & & 0.23714 & 0.27511 \\
& US & 0.09218 & 0.01663 & & -0.16351 \\
& HK & -0.07099 & 0.30083 & -0.22221 & \\
\hline P-value & & & & \\
& & Recipient & & HK \\
\hline Source & Greece & UK & 0.312 & 0.610 \\
& UK & 0.042 & 0.244 & 0.080 & 0.030 \\
& US & 0.278 & & & 0.860 \\
& HK & 0.618 & 0.462 & 0.884 & \\
\hline
\end{tabular}

To compare the result of the two tests, we compare Tables 4 and 6 for the equity market, and compare Tables 5 and 7 for the real estate market. From the above tables, we can see that for both equity and real estate markets, the estimations $\hat{\gamma}_{j, i}$ and $\hat{\gamma}_{j, i}^{*}$ of the coefficient $\gamma_{j, i}$ are roughly the same in value, and their $\mathrm{p}$ values are similar, too. This is natural because in the case-resampling bootstrap method, we select $T$ observations from the given sample randomly each time, so the estimated value $\hat{\gamma}_{j, i}^{*}$ of the coefficient $\gamma_{j, i}$ should be close to the OLS estimator $\hat{\gamma}_{j, i}$, and the p-values of the two estimators should not differ too much.

In comparison, Hatemi-J and Hacker (2005)'s result showed that the OLS and the case-resampling bootstrap method gave similar estimated values of the coefficients, but the $\mathrm{p}$-values based on the case-resampling bootstrap method was much smaller, i.e. there was a much more significant evidence of contagion. On the contrary, the result given by Hatemi-J and Roca (2010) showed no significant evidence of contagion. The discrepancies between the results are due to the fact that the observations are selected randomly from the given sample in the case-resampling bootstrap method. Comparing with Hatemi-J and Hacker (2005), Hatemi-J and Roca (2010)'s method, our method has an advantage that we test all combinations of contagious linkages, but Hatemi-J and Hacker (2005), Hatemi- 
$\mathrm{J}$ and Roca (2010) assumed a fixed source of contagion.

\section{CONCLUSION}

In this paper, we use the FRM test and the case-resampling bootstrap method to investigate contagion across equity and real estate markets of four countries during the European sovereign debt crisis. The results are given in Section 5. From the results, we can see that the overall effect of contagion is not so great. For equity markets, the major pattern of contagion is between Greece and U.S. (in both directions), and between U.K. and Hong Kong (in both directions). For real estate markets, the major pattern of contagion is between U.K. and Hong Kong (in both directions), and from U.K. to Greece (for the case-resampling bootstrap method only). Our results have the following practical implication to investors. If there is significant evidence of contagion from a type of asset price of one country to that type of asset price of another country (e.g. Hong Kong $\leftrightarrow$ U.K. for both equity and real estate markets in our case), holding that type of asset of both countries together would suffer because they would tend to move together in the same direction. Therefore, investors and portfolio managers should constantly review their portfolio to avoid loss caused by contagion. This also applies to real estate investment and will lead to better strategic property management.

One observation which can be seen from the result is that the patterns of contagion in the equity and real estate markets are different. Most of the previous work of contagion focused on equity markets. There aren't so many previous studies on contagion across real estate markets since it is difficult to find a reliable, accurate and high-frequency real estate index. Therefore, mixed results occurred (refer to Section 2), and the contagion pattern of the real estate markets is not fully explored. Our result shows that the real estate markets have a different contagion pattern from the equity markets. There are two main reasons for this.
Firstly, the real estate market is a special type of asset market which behaves differently from other types of asset markets such as the equity market. As mentioned in introduction, real estate can serve as both consumption goods and an investment tool. This special feature of real estate makes it behave differently from other types of assets such as equity. Secondly, the government can take a more active role in the real estate market than in the equity market. The government can control the supply of land and housing by monitoring the number of land auctions and building public housing estates. Thus the real estate market is more easily affected by government manipulation and hence may behave in a way different from the equity market.

Another finding is that the FRM test and the case-resampling bootstrap method give similar results. However, this does not mean that the case-resampling bootstrap method has no use at all. As mentioned, traditional methods like the Chow test do not work well when the data is not normally distributed or has non-constant variance. Our result shows that the null hypothesis of normality is strongly rejected. Thus alternative methods have to be used. The case-resampling bootstrap method has the advantage that it performs accurately under non-normality and heteroscedasticity, so it can provide clear and reasonable results.

Both of the tests we use fail to show the expected result that Greece is the main source of contagion. There are a number of reasons for this. Firstly, the European sovereign debt crisis is a new crisis which is still ongoing. Up till now, there are still no publications studying contagion patterns during this crisis. Secondly, countries like Greece are emerging markets which previous work seldom studied on. They may not behave in the same way as the markets of the developed countries do. Furthermore, only a few of the previous studies used the case-resampling bootstrap method to test contagion. In particular, no one has ever used this method to investigate contagion during the European sovereign debt crisis. This paper gives a first insight of contagion across Greece 
and the major economies in the world during the European sovereign debt crisis.

Hatemi-J and Hacker (2005) applied the case-resampling bootstrap method to the univariate linear regression model, and we extend their method to the multivariate model so that all combinations of contagious linkages can be tested. However, there are many kinds of models of contagion besides the linear regression model. The application of the case-resampling bootstrap method to other models would be a scope of future research.

\section{ACKNOWLEDGEMENT}

We are grateful for the financial support from the PolyU Internal Research Grants (Project \#G-YK32, 4-ZZC8 and 4-ZZC4).

\section{REFERENCES}

Bond, S. A., Dungey, M. and Fry, R. (2006) A web of shocks: crises across Asian real estate markets, The Journal of Real Estate Finance and Economics, 32(3), pp. 253-274. http://dx.doi.org/10.1007/s11146-0066800-0

Case, B., Yang, Y. and Yildirim, Y. (2012) Dynamic correlations among asset classes: REIT and stock returns, The Journal of Real Estate Finance and Economics, 44(3), pp. 298-318. http://dx.doi.org/10.1007/s11146010-9239-2

Dungey, M. (2009) The tsunami: measures of contagion in the 2007-08 credit crunch, CESifo Forum, 9(4), pp. 33-43.

Dungey, M., Fry, R., González-Hermosillo, B. and Martin, V. L. (2005a) Empirical modelling of contagion: a review of methodologies, Quantitative Finance, 5(1), pp. 9-24. http://dx.doi. org/10.1080/14697680500142045

Dungey, M., Fry, R., Gonzalez-Hermosillo, B. and Martin, V. L. (2005b). Sampling properties of contagion tests, mimeo. Australian National University.

Forbes, K. J. and Rigobon, R. (2002) No contagion, only interdependence: measuring stock market comovements, The Journal of Finance, 57(5), pp. 2223-2261. http://dx.doi.org/10.1111/0022-1082.00494

Fry, R., Martin, V. L. and Tang, C. (2010) A new class of tests of contagion with applications to real estate markets, Journal of Business and Economic Statistics, 28(3), pp. 423-437. http://dx.doi.org/10.1198/ jbes.2010.06060

Hatemi-J, A. and Hacker, R. S. (2005) An alternative method to test for contagion with an application to the Asian financial crisis, Applied Financial
Economics Letters, 1(6), pp. 343-347. http://dx.doi. org/10.1080/17446540500393468

Hatemi-J, A. and Roca, E. (2010) The impact of the US real estate market on other major markets during normal and crisis periods, Working Paper.

Hudson-Wilson, S., Fabozzi, F. J. and Gordon, J. N. (2003) Why real estate?, The Journal of Portfolio Management, 29(5), pp. 12-25. http://dx.doi.org/10.3905/ jpm.2003.319902

Hui, E. C. M. and Chan, K. K. K. (2012) Are the global real estate markets contagious?, International Journal of Strategic Property Management, 16(3), pp. 219-235. http://dx.doi.org/10.3846/1648715X.2011.645904

Hui, E. C. M., and Zheng, X. (2012a) Exploring the dynamic relationship between housing and retail property markets: an empirical study of Hong Kong, Journal of Property Research, 29(2), pp. 85-102. http://dx.doi. org/10.1080/09599916.2012.674968

Hui, E. C. M. and Zheng, X. (2012b) The dynamic correlation and volatility of real estate price and rental: an application of MSV model, Applied Economics, 44(23), pp. 2985-2995. http://dx.doi.org/10.1080/000 36846.2011.568409

Hui, E. C. M., Zuo, W. J. and Hu, L. (2011) Examining the relationship between real estate and stock markets in Hong Kong and the United Kingdom through data mining, International Journal of Strategic Property Management, 15(1), pp. 26-34. http://dx.doi.org/10.3 846/1648715X.2011.565867

Knight, J., Lizieri, C. and Satchell, S. (2005) Diversification when it hurts? The joint distributions of real estate and equity markets, Journal of Property Research, 22(4), pp. 309-323. http://dx.doi. org/10.1080/09599910600558520

Liow, K. H. (2012) Co-movements and correlations across Asian securitized real estate and stock markets, Real Estate Economics, 40(1), pp. 97-129. http://dx.doi. org/10.1111/j.1540-6229.2011.00314.x

Liow, K. H. (2006) Dynamic relationship between stock and property markets, Applied Financial Economics, 16(5), pp. 371-376. http://dx.doi. org/10.1080/09603100500390885

Liow, K. H. (2008) Financial crisis and asian real estate securities market interdependence: some additional evidence, Journal of Property Research, 25(2), pp. 127155. http://dx.doi.org/10.1080/09599910802605400

Okunev, J. and Wilson, P. (1997) Using nonlinear tests to examine integration between real estate and equity markets, Real Estate Economics, 25(3), pp. 487-503. http://dx.doi.org/10.1111/1540-6229.00724

Okunev, J., Wilson, P. and Zurbruegg, R. (2000) The causal relationship between real estate and stock markets, The Journal of Real Estate Finance and Economics, 21(3), pp. 251-261. http://dx.doi. org/10.1023/A:1012051719424

Pericoli, M. and Sbracia, M. (2003) A primer on financial contagion, Journal of Economic Surveys, 17(4), pp. 571608. http://dx.doi.org/10.1111/1467-6419.00205 
Quan, D. C. and Titman, S. (1999) Do real estate prices and stock prices move together? An international analysis, Real Estate Economics, 27(2), pp. 183-207. http://dx.doi.org/10.1111/1540-6229.00771

Ryan, L. (2011) Nowhere to hide: an analysis of investment opportunities in listed property markets during financial market crises, Journal of Property Research, 28(2), pp. 97-131. http://dx.doi.org/10.1080/0 9599916.2010.502005

Serrano, C. and Hoesli, M. (2012) Fractional cointegration analysis of securitized real estate, The Journal of Real Estate Finance and Economics, 44(3), pp. 319 338. http://dx.doi.org/10.1007/s11146-009-9231-x

The World Bank Group (2011) Definitions of contagion. [Online] Available at: http://go.worldbank.org/JIBDRK3YC0 [accessed 3 August 2011]

Tse, R. Y. C. (2001) Impact of property prices on stock prices in Hong Kong, Review of Pacific Basin Financial Markets and Policies, 4(1), pp. 29-43. http:// dx.doi.org/10.1142/S0219091501000309

Wilson, P. J., Stevenson, S. and Zurbruegg, R. (2007) Measuring spillover effects across Asian property stocks, Journal of Property Research, 24(2), pp. 123138. http://dx.doi.org/10.1080/09599910701440081

Wilson, P. and Zurbruegg, R. (2004) Contagion or interdependence? Evidence from comovements in Asia-Pacific securitised real estate markets during the 1997 crisis, Journal of Property Investment \& Finance, 22(5), pp. 401-413. http://dx.doi. org/10.1108/14635780410556889

Yunus, N. (2009) Increasing convergence between U.S. and international securitized property markets: evidence based on cointegration tests, Real Estate Economics, 37(3), pp. 383-411. http://dx.doi.org/10.1111/j.15406229.2009.00246.x

Yunus, N. and Swanson, P. E. (2007) Modelling linkages between US and Asia-Pacific securitized property markets, Journal of Property Research, 24(2), pp. 95122. http://dx.doi.org/10.1080/09599910701439992

Zhou, J. (2010) Comovement of international real estate securities returns: a wavelet analysis, Journal of Property Research, 27(4), pp. 357-373. http://dx.doi. org/10.1080/09599916.2010.517853 